\title{
Quality by Design-driven investigation of the mechanical properties of mucoadhesive films for needleless anesthetics administration
}

\author{
Luiz Fernando Machado Ferreira1', Douglas Vieira Thomaz² (D), Maíra Peres Ferreira Duarte,

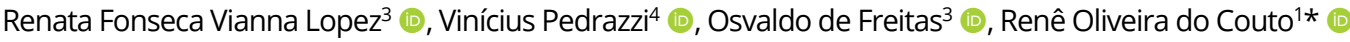 \\ ${ }^{1}$ Campus Centro-Oeste Dona Lindu (CCO), Universidade Federal de São João del Rei (UFSJ), Divinópolis, MG, Brasil \\ ${ }^{2}$ Faculdade de Farmácia (FF), Universidade Federal de Goiás (UFG), Goiânia, GO, Brasil \\ ${ }^{3}$ Faculdade de Ciências Farmacêuticas de Ribeirão Preto (FCFRP), Universidade de São Paulo (USP), Ribeirão Preto, SP, Brasil \\ ${ }^{4}$ Faculdade de Odontologia de Ribeirão Preto (FORP), Universidade de São Paulo (USP), Ribeirão Preto, SP, Brasil \\ *Corresponding author: rocouto@ufsj.edu.br
}

\begin{abstract}
Objectives: To systematically evaluate the effects of hydroxypropyl methyl cellulose (HPMC) type (E5LV, E15LV, and K100LV); plasticizer type (glycerol and mannitol), plasticizer loading ( 0.12 and $0.24 \% \mathrm{~W} / \mathrm{w})$; and loading of prilocaine and lidocaine hydrochlorides combined at $1: 1$ ratio $\left(0\right.$ and $\left.47 \mathrm{mg} / \mathrm{cm}^{2}\right)$ in the mechanical properties of buccal films. Methods: A quality by design (QbD) approach based on a full factorial design $\left(3 \times 2^{3}\right)$ and complementarily multivariate statistical tools i.e., principal component analysis (PCA), response surface methodology (RSM), and correlation matrix were used in this pursuit. The thickness, elongation at break, tensile strength, force at break, and Young 's modulus of the anesthetic buccal films obtained by solvent casting were assessed. Results: The QbD, PCA and RSM altogether demonstrated that all studied formulation variables, mainly the drug loading, affect the mechanical properties of the films at different significance levels. The multivariate analysis yielded the modelling of elongation at break, tensile strength, and force at break, which significantly correlated with each other. The drugs exerted a synergic plasticizing effect on the films, and the use of HPMC K100 LV (with greater hydroxypropyl substitution degree and viscosity) and mannitol favored their elasticity and resistance. Furthermore, the majority of the films fulfilled the requirements for buccal administration due to their softness and mechanical resistance. Conclusion: Mannitol is suitable plasticizer for manufacturing HPMC anesthetic buccal films with improved mechanical properties. These results are a step forward in the rational development of formulations for the replacement of needles in dentistry.
\end{abstract}

Keywords: Biocompatible Materials. Buccal Drug Administration. Hypromellose Derivatives. Lidocaine Prilocaine Drug Combination. Multivariate analysis. Polymers.

\section{How to cite}

Ferreira LFM, Thomaz DV, Duarte MPF, Lopez RFV, Pedrazzi V, Freitas O, Couto RO. Quality by Design-driven investigation of the mechanical properties of mucoadhesive films for needleless anesthetics administration. Rev Ciênc Farm Básica Apl. 2021;42:e707.

https://doi.org/10.4322/2179-443X.0707

\footnotetext{
Financial support: ROC, OF, VP, RFVL - received financial support from São Paulo Research Foundation - FAPESP (project awards 2012/07251-6, 2012/ 064787 and 2014/22451-7), and Brazilian National Council for Scientific and Technological Development - CNPq (project awards 472817/2012-4 and 429465/2016-5); LFMF - received research grant from Universidade Federal de São João del Rei (PIBIC/CNPq Process: 17721); MPFD, DVT - none.

Conflicts of interest: ROC no conflict of interest; OF no conflict of interest; VP no conflict of interest; RFVL no conflict of interest; LFMF no conflict of interest; MPFD no conflict of interest; DVT no conflict of interest.

The study was carried out at Campus Centro-Oeste Dona Lindu (CCO), Universidade Federal de São João del Rei (UFSJ), Divinópolis, MG, Brasil; and Faculdade de Ciências Farmacêuticas de Ribeirão Preto (FCFRP), Universidade de São Paulo (USP), Ribeirão Preto, SP, Brasil.

Received on October 15, 2020. Accepted on November 20, 2020.
} 


\section{INTRODUCTION}

Over the last decade, our research group has contributed with the development of noninvasive mucoadhesive anesthetic delivery platforms, envisioning the successful replacement of needles in buccal anesthesia ${ }^{1-4}$. This technological strategy has been pursued since needle punctures in dentistry are remarkably painful and uncomfortable, often scaring away patients from dental offices, impairing the treatment success and the quality of life of the patients ${ }^{5}$. Moreover, injectable anesthesia is a great concern for dentists worldwide due to the possibility of causing labor accidents, contamination, and intoxication for both dentist and patient $t^{6,7}$.

Among our previous findings, the clinical efficacy of mucoadhesive anesthetic films in reducing both the shallow and deep painful sensation associated with simulated buccal infiltration injections was noteworthy. These round films $\left(0.64 \mathrm{~cm}^{2}\right)$ were comprised of a combination amino amide salts, i.e., prilocaine (PRC) and lidocaine (LDC) hydrochlorides at the ratios 1:1 (22 $\mathrm{mg}), 1: 2(33 \mathrm{mg})$ and 1:4 (55 $\mathrm{mg})$; and the biocompatible materials hydroxypropyl methyl cellulose (HPMC) K100 LV as a hydrophilic and mucoadhesive polymeric matrix; and the polyalcohol glycerol as plasticizer ${ }^{3}$. The results showed that these films were able to induce the anesthetic plan within $5 \mathrm{~min}$, and to maintain anesthesia for $50 \mathrm{~min}$ in adult patients. Moreover, the films presented suitable mucoadhesion both in vitro and in vivo, being safe and very well tolerated by the patients.

Envisioning the rational and full technological development of a needleless mucoadhesive drug delivery platform, besides the quality attributes related to the efficacy and safety, it is necessary to evaluate and control the features related to the manufacture and scale up of production, such as the elasticity, plasticity, flexibility and mechanical resistance of the films ${ }^{8}$. In this sense, some key points are of upmost importance to be addressed, namely: i) do the drugs exert a synergic plasticizing effect?; ii) will decreasing HPMC viscosity affect the mechanical properties of the films?; iii) will replacing glycerol with a more hydrophilic plasticizer such as mannitol impact the mechanical properties of the films?; and iv) how do the mechanical properties of the films correlate with each other?

Typically, the relationships between formulation, process variables, and performance characteristics are not well understood given the inherent complexity of this approach. Therefore, the quantitative prediction of the performance of a formulation as a function of the physical and physicochemical properties of its constituents is a difficult task, which presents one of the greatest challenges for formulation scientists of both academy and industry ${ }^{9}$.

Several multivariate analysis statistical tools can be used as quality by design (QbD) approaches to facilitate the understanding of correlations between the factors involved in the development of drug delivery systems e.g., fractional and complete factorial design, principal component analysis (PCA), and response surface methodology (RSM) ${ }^{10}$; artificial neural networks ${ }^{11}$; and decision trees ${ }^{12}$. In essence, the application of these tools aims at both the systematic evaluation of the effects of factors by themselves, as well as their interactions on the various product performance characteristics with a reduced number of experiments ${ }^{13}$.

In this context, the aim of this work was to systematically evaluate the effects of HPMC type, plasticizer type, loading and anesthetic loading towards optimizing the mechanical properties of mucoadhesive films intended for buccal anesthesia. Therefore we used the QbD approach of a full factorial design and complementarily multivariate statistical tools namely PCA, RSM, and correlation matrix in order to evaluate the influence of each parameter in the mechanical properties of the delivery system. 


\section{MATERIAL AND METHODS}

\subsection{Polymers, plasticizers, drugs and chemicals}

Different types of HPMC i.e., Methocel ${ }^{\mathrm{TM}}$ E5 LV Premium lot 3E210124L1 (96.4\% w/w content; $28.6 \%$ methoxyl substitution; $8.67 \%$ hydroxypropyl substitution; $0.7 \% \mathrm{w} / \mathrm{w}$ total ash; $0.7 \% \mathrm{w} / \mathrm{w}$ sulfated ash; $2.2 \% \mathrm{w} / \mathrm{w}$ moisture; $5.2 \mathrm{mPa} / \mathrm{s}$ viscosity at $2 \% \mathrm{w} / \mathrm{w}$ dispersion in water; pH 6.7); Methoce $\mathrm{I}^{\mathrm{TM}}$ E15 LV Premium Lot D011F29L01 (97.0\% w/w content; $28.1 \%$ methoxyl substitution; $9.0 \%$ hydroxypropyl substitution; $0.4 \% \mathrm{w} / \mathrm{w}$ total ash; $0.4 \% \mathrm{w} / \mathrm{w}$ sulfated ash; $2.2 \% \mathrm{w} / \mathrm{w}$ moisture; $15.4 \mathrm{mPa} / \mathrm{s}$ viscosity at $2 \% \mathrm{w} / \mathrm{w}$ dispersion in water; $\mathrm{pH} 6.5$ ); and Methoce ${ }^{\mathrm{TM}} \mathrm{K} 100$ LV Premium lot WP437291 (95.7\% w/w content; $22.5 \%$ methoxyl substitution; $9.6 \%$ hydroxypropyl substitution; $0.9 \% \mathrm{w} / \mathrm{w}$ total ash; $0.9 \% \mathrm{w} / \mathrm{w}$ sulfated ash; $2.5 \% \mathrm{w} / \mathrm{w}$ moisture; $99 \mathrm{mPa} / \mathrm{s}$ dispersion viscosity at $2 \% \mathrm{w} / \mathrm{w}$ in water; $\mathrm{pH} 7.0$ ) were supplied by Colorcon $^{\circledR}$ (Cotia, SP, Brazil); Mannitol was obtained from Pharmanostra (Campinas, SP, Brazil); Glycerol was purchased from Sigma-Aldrich (St. Louis, Missouri, USA); PRC and LDC were purchased from Henrifarma ${ }^{\circledR}$ (São Paulo, SP, Brazil).

\subsection{Manufacture of anesthetic buccal films using QbD}

A $3 \times 2^{3}$ full factorial design was used as QbD strategy. The experimental design herein reported consisted of two categorical variables ( Pol $_{\mathrm{T}}$, hydrophilic polymer type; Plas $\mathrm{S}_{\mathrm{T}}$, plasticizer type) and two continuous variables (Plas, plasticizer loading; $D_{A}$, drug loading). Table 1 shows the studied factors and their respective coded and uncoded levels. The full factorial design matrix showing the combination of factors and their coded levels is presented in Table 2.

Table 1: Factors and coded and uncoded levels used in $3 \times 2^{3}$ full factorial design for the manufacture of mucoadhesive buccal films

\begin{tabular}{cccc}
\hline & \multicolumn{3}{c}{ Levels } \\
\cline { 2 - 4 } Factors & $\mathbf{- 1}$ & $\mathbf{0}$ & $\mathbf{1}$ \\
\hline $\mathrm{X}_{1} \cdot \mathrm{Pol}_{\mathrm{T}}(-)$ & HPMC E5LV & HPMC E15LV & HPMC K100LV \\
$\mathrm{X}_{2} \cdot \mathrm{Plas}_{\mathrm{T}}(-)$ & glycerol & - & mannitol \\
$\mathrm{X}_{3} \cdot \mathrm{PlaS}_{\mathrm{A}}(\% \mathrm{~W} / \mathrm{w})$ & 0.12 & - & 0.24 \\
$\mathrm{X}_{4} \cdot \mathrm{D}_{\mathrm{A}}\left(\mathrm{mg} / \mathrm{cm}^{2}\right)$ & 0 & - & $47^{*}$ \\
\hline
\end{tabular}

$\mathrm{X}_{\mathrm{n}}$, evaluated factor; Pol, polymer type; Plast, plasticizer type; Plas $\mathrm{A}_{\mathrm{A}}$, plasticizer loading in relation to polymer mass; $D_{A}$, drug loading (PRC and LDC combined at a 1:1 ratio per $\mathrm{cm}^{2}$ ); *Equivalent to a total of $13.6 \%(\mathrm{w} / \mathrm{w})$ in the dispersion.

Table 2: Full factorial design matrix $\left(3 \times 2^{3}\right)$ and results of mechanical properties of anesthetic buccal films

\begin{tabular}{cccccccccc}
\hline Films & $\mathbf{X}_{\mathbf{1}}$ & $\mathbf{X}_{\mathbf{2}}$ & $\mathbf{X}_{\mathbf{3}}$ & $\mathbf{X}_{\mathbf{4}}$ & $\mathbf{T}(\boldsymbol{\mu m})$ & $\mathbf{E}(\%)$ & TS (Mpa) & FB (N) & Ym (Mpa) \\
\hline 1 & -1 & -1 & -1 & -1 & $60.3(18.7)$ & $-3.9(0.6)$ & $54.6(9.4)$ & $19.3(1.3)$ & $-14.4(4.9)$ \\
2 & -1 & -1 & -1 & 1 & $427.3(23.1)$ & $28.1(5.8)$ & $0.6(0.1)$ & $1.3(0.3)$ & $0.02(0.001)$ \\
3 & -1 & -1 & 1 & -1 & $45.4(9.7)$ & $3.4(1.2)$ & $31.5(5.7)$ & $9.6(3.3)$ & $9.7(2.3)$ \\
4 & -1 & -1 & 1 & 1 & $347.3(39.4)$ & $84.3(10.6)$ & $0.6(0.1)$ & $1.1(0.2)$ & $0.01(0.001)$ \\
5 & -1 & 1 & -1 & -1 & $82.6(17.1)$ & $4.5(0.5)$ & $38.6(2.9)$ & $21.4(1.3)$ & $8.7(0.9)$ \\
6 & -1 & 1 & -1 & 1 & $352.9(19.6)$ & $51.8(4.6)$ & $2.5(0.2)$ & $5.3(0.5)$ & $0.1(0.001)$ \\
7 & -1 & 1 & 1 & -1 & $81.2(23.5)$ & $4.6(0.7)$ & $50.1(10.9)$ & $25.2(2.4)$ & $11.0(2.7)$ \\
8 & -1 & 1 & 1 & 1 & $346.5(34.4)$ & $41.1(4.0)$ & $2.6(0.2)$ & $5.2(0.6)$ & $0.1(0.001)$ \\
\hline
\end{tabular}




\begin{tabular}{cccccccccc}
\hline Films & $\mathbf{X}_{\mathbf{1}}$ & $\mathbf{X}_{\mathbf{2}}$ & $\mathbf{X}_{\mathbf{3}}$ & $\mathbf{X}_{\mathbf{4}}$ & $\mathbf{T}(\boldsymbol{\mu m})$ & $\mathbf{E}(\%)$ & TS (Mpa) & FB (N) & Ym (Mpa) \\
\hline 9 & 0 & -1 & -1 & -1 & $111.1(10.0)$ & $9.3(1.7)$ & $23.5(3.3)$ & $16.2(2.4)$ & $2.6(0.3)$ \\
10 & 0 & -1 & -1 & 1 & $361.2(27.7)$ & $78.1(8.1)$ & $5.4(0.8)$ & $11.5(1.1)$ & $0.1(0.01)$ \\
11 & 0 & -1 & 1 & -1 & $99.9(29.5)$ & $13.4(3.7)$ & $24.1(3.5)$ & $14.1(4.1)$ & $1.9(0.3)$ \\
12 & 0 & -1 & 1 & 1 & $354.2(24.9)$ & $92.6(5.5)$ & $2.6(0.3)$ & $5.6(0.6)$ & $0.03(0.001)$ \\
13 & 0 & 1 & -1 & -1 & $81.5(11.7)$ & $17.5(2.6)$ & $59.9(5.6)$ & $30.3(2.1)$ & $3.5(0.6)$ \\
14 & 0 & 1 & -1 & 1 & $378.1(42.3)$ & $74.4(8.3)$ & $4.6(0.5)$ & $10.3(0.5)$ & $0.1(0.01)$ \\
15 & 0 & 1 & 1 & -1 & $83.0(7.4)$ & $5.1(0.7)$ & $51.7(8.4)$ & $24.7(2.6)$ & $10.1(1.4)$ \\
16 & 0 & 1 & 1 & 1 & $368.0(97.7)$ & $71.5(6.4)$ & $5.7(0.5)$ & $14.6(1.1)$ & $0.1(0.01)$ \\
17 & 1 & -1 & -1 & -1 & $103.5(14.6)$ & $14.4(6.8)$ & $29.3(3.8)$ & $18.5(3.4)$ & $2.4(1.0)$ \\
18 & 1 & -1 & -1 & 1 & $359.1(33.7)$ & $68.6(6.2)$ & $5.7(1.3)$ & $12.3(1.9)$ & $0.1(0.02)$ \\
19 & 1 & -1 & 1 & -1 & $110.6(19.4)$ & $25.8(7.7)$ & $46.8(4.1)$ & $34.8(3.1)$ & $1.9(0.4)$ \\
20 & 1 & -1 & 1 & 1 & $364.0(69.4)$ & $137.1(8.6)$ & $10.0(1.4)$ & $24.0(3.1)$ & $0.1(0.01)$ \\
21 & 1 & 1 & -1 & -1 & $69.9(16.2)$ & $15.2(3.1)$ & $51.4(4.2)$ & $20.7(3.1)$ & $3.5(0.7)$ \\
22 & 1 & 1 & -1 & 1 & $339.2(68.8)$ & $91.2(7.5)$ & $6.9(1.2)$ & $13.1(1.7)$ & $0.1(0.01)$ \\
23 & 1 & 1 & 1 & -1 & $68.8(9.5)$ & $19.8(4.9)$ & $70.4(6.5)$ & $28.1(7.3)$ & $3.7(0.5)$ \\
24 & 1 & 1 & 1 & 1 & $366.0(48.4)$ & $31.2(3.7)$ & $7.1(0.5)$ & $15.8(2.1)$ & $0.2(0.03)$ \\
\hline
\end{tabular}

$\mathrm{X}_{\mathrm{n}}$, evaluated factor (see Table S1); T, thickness, E, elongation at break; TS, tensile strength; FB, force at break; Ym, Young `s moduli; Results expressed as average(SD) of $n>5$.

A total of 24 films were obtained by the solvent casting technique ${ }^{3}$. Briefly, the plasticizer was homogenized in distilled water, and the drugs PRC and LDC were dissolved in this solution at $1: 1$ ratio $\left(13.6 \% \mathrm{w} / \mathrm{w}\right.$, equivalent to $47 \mathrm{mg}$ of drug per $\left.\mathrm{cm}^{2}\right)$. Thereafter, the polymer ( $3 \%$ $\mathrm{w} / \mathrm{w}$ ) was dispersed while the whole solution underwent gentle agitation on a mechanical shaker at $300 \mathrm{rpm}$ for $12 \mathrm{~h}$. After resting for $1 \mathrm{~h}$ at room temperature to remove entrapped bubbles, the dispersions ( $50 \mathrm{~g}$ ) were carefully spread on polycarbonate plates of $144 \mathrm{~cm}^{2}$ total area. The plates were placed in an oven at $40 \pm 1{ }^{\circ} \mathrm{C}$ for 12 hours to dry the dispersions. The free films were kept until the moment of use in a desiccator at $25^{\circ} \mathrm{C}$ and relative humidity of $53{ }^{\circ} \mathrm{C}$. $\pm 2 \%$. Desiccator internal conditions were obtained with magnesium nitrate hexahydrate saturated solution

\subsection{Characterization of anesthetic buccal films}

The visual and tactile aspect evaluation was conducted to select only homogeneous, flexible, uniformly colored films that did not present insoluble particles, fractures, or fragile areas $^{3}$. The thickness $(T, \mu \mathrm{m})$ was determined by performing 10 random measurements on different parts of the film sample using a digital micrometer (Starrett ${ }^{\circledR}$, Athol, MA, USA).

The mechanical properties of the films were evaluated using a tensile modulus TA XT plus texture analyzer according to ASTM D882-Method $02{ }^{14}$. Samples with $6 \mathrm{~mm}$ width and $80 \mathrm{~mm}$ length were obtained using a polycarbonate mold and stainless-steel blade, and their thicknesses were recorded in sextuplicate before analysis. The ends of the specimens $(1 \mathrm{~cm})$ were covered with tape to prevent entrapment by the equipment's clamping jaws, which would cause the appearance of breakpoints. The samples were vertically oriented, with their ends positioned and fixed exactly in the center of the claws.

A $50 \mathrm{Kg}$ load cell was used, with a test speed of $1 \mathrm{~mm} / \mathrm{s}$ and a maximum elongation of $190 \%$. The analyzes $(n \geq 5)$ were performed at room temperature $\left(25 \pm 2^{\circ} \mathrm{C}\right)$. Based on the obtained stress $x$ strain curves, tensile strength (TS, MPa) was calculated by dividing the strength at 
break ( $F B, N$ ) by the cross-sectional area of the film (width $x$ initial thickness). The elongation percentage at break $(E, \%)$ was determined by dividing the values of the differential break at the initial claw separation $(60 \mathrm{~mm})$ and multiplied by 100 . The elasticity module or Young's modulus (Ym, MPa) was calculated by the relation: TS/E ${ }^{8}$.

\subsection{Multivariate statistical analysis}

In order to correlate results and establish a statistical model capable of explaining the findings, PCA was used ${ }^{13}$. This approach was selected with the aim of minimizing dimensions based on the variance/correlation matrix of the datasets herein gathered, and segregate findings between common features of the formulations. To simplify interpretation of the relationships between the properties of the films, a correlation matrix was prepared. Data was analyzed using the Origin Pro $9 \mathrm{~b}^{\circledR}$ software package (Northampton, MA, USA).

Analysis of variance (ANOVA) and correlation analyses were performed by RSM in order to accurately determine the effects of the evaluated factors in the properties of the films. For this, the module "Industrial Statistics \& Six Sigma - Experimental Design (DOE)" of the Statistica 7 software package (Statsoft Inc., Tulsa, OK, USA) was used. Due to the great amplitude scale in the results of the dependent variables (i.e., responses), to enable the RSM analysis we normalized the data between -1 and +1 by applying the following mathematical rule displayed by Equation (1):

Normalized value $=\frac{(\text { real value }- \text { average value })}{(\text { greatest value }- \text { lowest value })}$

The response function applied was a quadratic polynomial equation, given by Equation (2):

$Y=\beta_{0}+\beta_{1} X_{1}+\beta_{2} X_{2}+\beta_{3} X_{3}+\beta_{4} X_{4}+\beta_{11} X_{1}^{2}+\beta_{12} X_{1} X_{2}+\beta_{13} X_{1} X_{3}+\beta_{14} X_{1} X_{4}+$

$\beta_{23} X_{2} X_{3}+\beta_{24} X_{2} X_{4}+\beta_{34} X_{3} X_{4}+\beta_{112} X_{1}^{2} X_{2}+\beta_{113} X_{1}^{2} X_{3}+\beta_{114} X_{1}^{2} X_{4}$

In Equation (2), $Y$ is the predicted response (dependent variable i.e., T, E, TS, FB and $Y m$ ); $\beta_{0}$ is the model constant; $X_{n}$ are the independent variables (i.e., Pol ${ }_{\mathrm{T}}, \mathrm{Plas}_{\mathrm{T}}, \mathrm{Plas}_{\mathrm{A}}$, and $\mathrm{D}_{\mathrm{A}}$ ); $\beta_{n}$ are linear coefficients; $\beta_{n n}$ are the quadratic coefficients; and $\beta_{n N}$ are the cross product coefficients.

When applicable, pairwise comparisons of averages were performed by Student 's T test. All analysis considered a confidence interval which was set to 0.95 and statistical significance was attributed to $p<0.05$.

\section{RESULTS}

\subsection{Mechanical properties of the mucoadhesive buccal films}

The results obtained in the characterization of the films are presented in Table 2. As expected, there was great variation in the properties of the different films and, due to the multifactorial nature inherent in the proposed experimental design, only PCA and RSM can satisfactorily explain the observed trends.

Overall, the drug loaded films were thicker, more plastic, less resistant and less elastic as compared to their respective unloaded samples ( $p<0.05$, Student 's T Test). The more plastic film was the loaded, comprising HPMC K100 LV and 0.24\% glycerol (exp. 20), while the unloaded film made with HPMC E5 LV and $0.12 \%$ glycerol (exp. 1) was the harder and more brittle. The stronger film was the unloaded and contained HPMC K100 LV and $0.24 \%$ mannitol (exp. 23). In turn, the more elastic film was unloaded and contained HPMC E5 LV and 0.24\% mannitol (exp. 7). 


\subsection{The effect of HPMC type, plasticizer and drug loading}

In order to propose a suitable model to explain the highest amount of variance in all data, as well as minimize their dimensions, a PCA approach was conducted, and the first two principal components (PCs) were selected according to their eigenvalues and the explained percentage of variance. Results are shown in Figure 1 in which the numbers correspond to the film composition as displayed in Table 2.

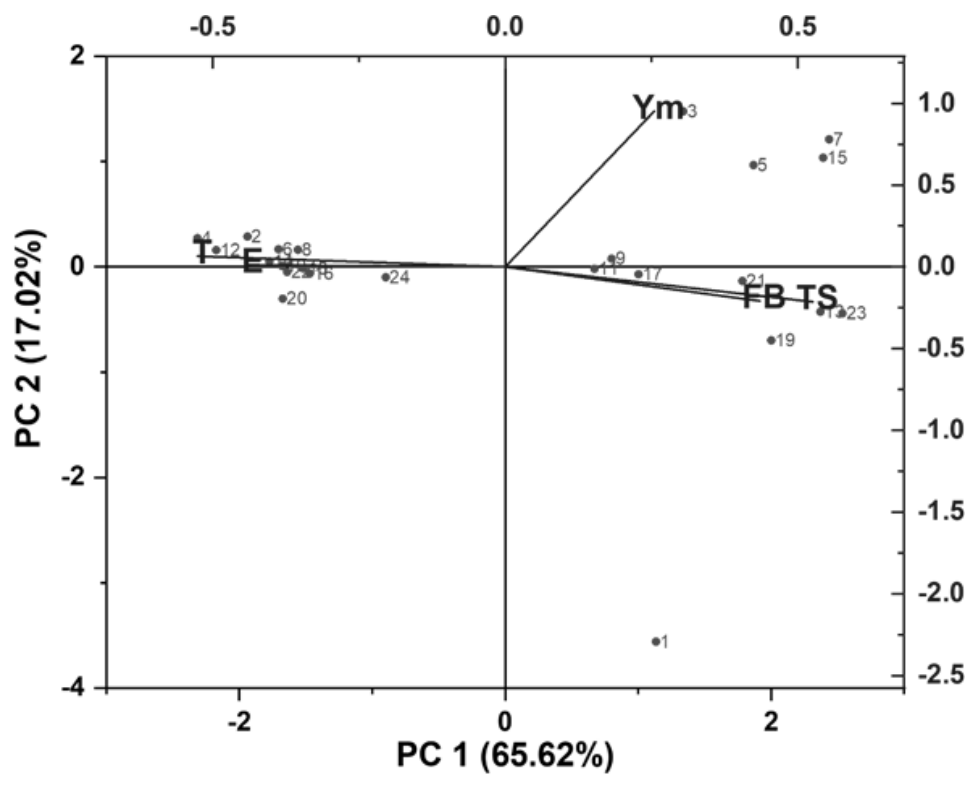

Figure 1. PCA byplot showcasing the scores data as scatter and eigenvectors plotted through scaled eigenvalues by their respective square roots All eigenvectors start at the mean.

PCA results showcased that PC1 and PC2 explained about $83 \%$ of all variance in the data, and such a cumulative effect enabled the separation of data into two major groups i.e., even number (left, drug loaded films) and odd numbers (right, unloaded films). Therefore, the anesthetic loading was the main factor affecting the mechanical properties of the delivery systems. Other PCs (i.e. PC3 up to PC8) were also analyzed, although their effect did not account for higher accuracy in the model herein studied, which led us thence to consider only the first two PCs.

Moreover, odd numbered data showed a clear segregation into three distinct subgroups (Figure 1), being one composed by the dataset of the film number 1, which presented the smallest clustering when compared to all other results. It is noteworthy that the two major groups were segregated by the horizontally depicted eigenvectors, whose variance is better explained by PC1. The even numbered group was segregated from the odd numbered group by vectors $\mathrm{T}$ and $\mathrm{E}$. These vectors converged and presented negative correlation to eigenvectors TS and FB, which also converged between themselves.

Eigenvector Ym presented small convergence towards the vectors which explained the odd numbered major group as well as even numbered group, and seemingly account for most of the explained variance by PC2, which can be further noticed by the dataset subgroup it apparently explains, namely films 3, 5, 15 and 7 . Thus, these can be considered the most elastic films.

The summary of the results obtained in the RSM is shown in Table 3, which presents the first and second order factors with their respective coefficients and degrees of significance. Bold values refer to significant coefficients, and the signs (+) and (-) signify effects directly and inversely proportional, respectively. Moreover, the prediction capacity of the obtained polynomial equations is represented by the respective determination coefficients $\left(R^{2}\right)$. In 
addition, Figures 2-4 show the response surface plots generated considering only significant factors according to the Pareto charts and the RSM results.

Table 3. Summary of RSM results in the analysis of mechanical properties of the anesthetic buccal films

\begin{tabular}{|c|c|c|c|c|c|}
\hline Factors & $T(\mu \mathrm{m})$ & $E(\%)$ & TS (Mpa) & FB (N) & Ym (Mpa) \\
\hline Intercept & $229.6^{C}$ & $45.2^{C}$ & $22.2^{c}$ & $15.9^{c}$ & +2.3 \\
\hline $\mathrm{Pol}_{T}$ & +2.4 & $+11.8^{A}$ & +2.9 & $+4.9^{c}$ & -0.2 \\
\hline $\mathrm{Pol}_{T}{ }^{2}$ & -9.3 & -6.7 & +3.3 & +0.1 & -0.6 \\
\hline Plas $_{T}$ & -2.9 & -3.1 & $+8.3^{\mathrm{A}}$ & $+4.1^{\mathrm{A}}$ & +1.2 \\
\hline Plas $_{A}$ & -3.3 & +0.4 & -1.2 & -1.2 & +0.7 \\
\hline$D_{A}$ & $+135.8^{c}$ & $+33.9^{c}$ & $-17.6^{C}$ & $-5.4^{\mathrm{B}}$ & -2.2 \\
\hline $\mathrm{Pol}_{T} x$ Plas & -4.8 & -4.9 & +2.3 & $-2.4^{\mathrm{A}}$ & -1.4 \\
\hline $\mathrm{Pol}_{T}{ }^{2} x$ Plas & -4.9 & -3.0 & -5.2 & -3.2 & +0.6 \\
\hline $\mathrm{Pol}_{T} x \mathrm{Plas}_{\mathrm{A}}$ & +8.8 & -1.8 & +3.3 & $+2.8^{\mathrm{A}}$ & -1.7 \\
\hline $\mathrm{Pol}_{T}{ }^{2} x$ Plas $_{A}$ & -0.7 & +4.5 & +3.0 & +3.2 & +0.9 \\
\hline $\mathrm{Pol}_{T} x \mathrm{D}_{\mathrm{A}}$ & -8.1 & +3.5 & +0.1 & +1.6 & +0.2 \\
\hline $\mathrm{Pol}_{T}{ }^{2} x$ Plas $_{A}$ & +6.8 & -5.8 & -3.4 & -0.8 & +0.6 \\
\hline $\mathrm{Plas}_{T} x$ Plas $_{\mathrm{A}}$ & +4.6 & $-10.1^{A}$ & +1.1 & +0.1 & -0.6 \\
\hline $\mathrm{Plas}_{T} x \mathrm{D}_{\mathrm{A}}$ & +0.1 & -5.5 & $-4.5^{A}$ & -1.2 & -1.5 \\
\hline $\operatorname{Plas}_{A} x D_{A}$ & -2.2 & +2.1 & -0.6 & +0.1 & -1.3 \\
\hline$R^{2}$ & $0.99^{A}$ & $0.90^{\mathrm{A}}$ & $0.94^{\mathrm{A}}$ & $0.92^{\mathrm{A}}$ & 0.64 \\
\hline
\end{tabular}

Pol ${ }_{T}$, polymer type; Plast, plasticizer type; Plas $A_{A}$ plasticizer loading in relation to polymer mass; $\mathrm{D}_{\mathrm{A}}$, drug loading (PRC and LDC combined at 1:1); T, thickness; E, elongation; TS, tensile strength; FB, force at break; Ym, Young `s modulus; $\mathrm{R}^{2}$, determination coefficient of the prediction mathematical model; Coefficients with + and - signs indicate direct and inversely proportional effects, respectively; Results marked in bold represent statistical significance (p) at: A5\%, ${ }^{B} 1 \%$ and ${ }^{\mathrm{C}} 0.1 \%$.
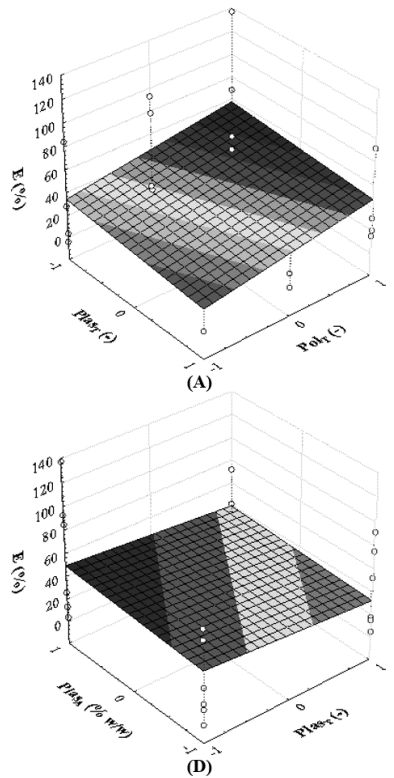
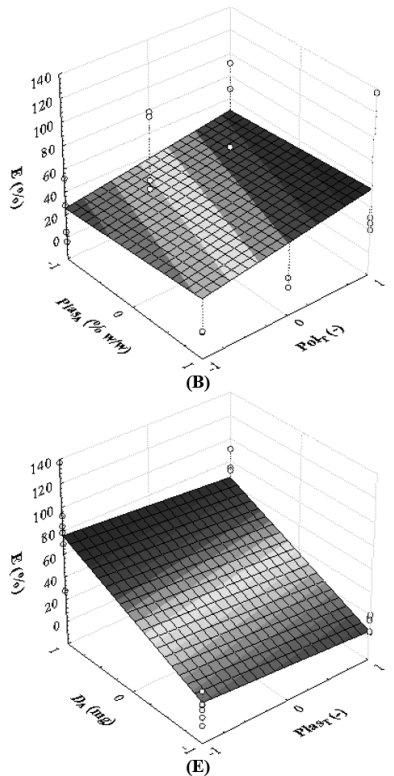

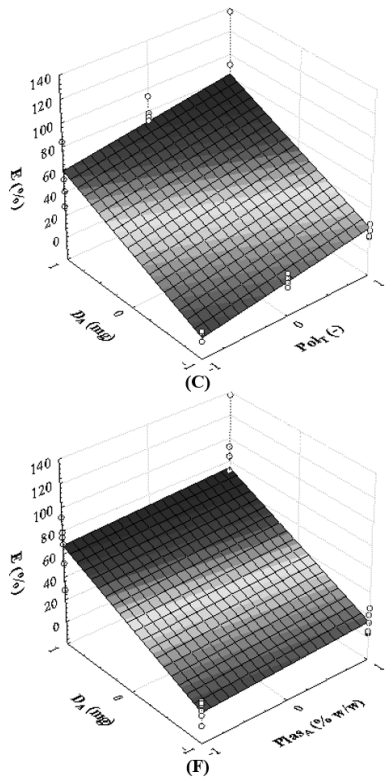

Figure 2: Response surface plots of elongation of the anesthetic buccal films as a function of (A) polymer type and plasticizer type; (B) polymer type and plasticizer loading; (C) polymer type and drug loading; (D) plasticizer type and plasticizer loading; (E) plasticizer type and drug loading; and

(F) plasticizer loading and drug loading. 

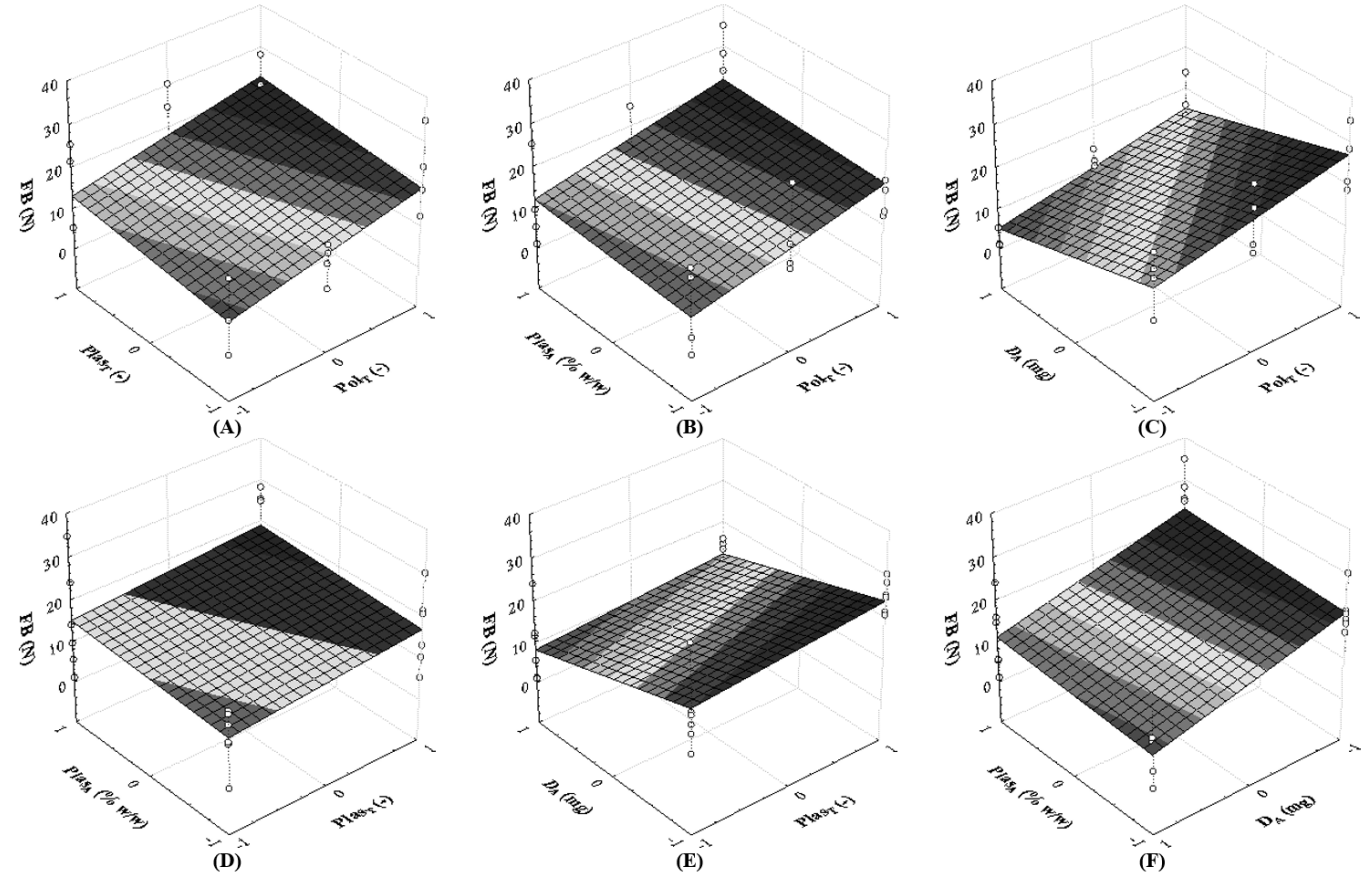

Figure 3: Response surface plots of force at break of the anesthetic buccal films as a function of (A) polymer type and plasticizer type; (B) polymer type and plasticizer loading; (C) polymer type and drug loading; (D) plasticizer type and plasticizer loading; (E) plasticizer type and drug loading; and

(F) plasticizer loading and drug loading.

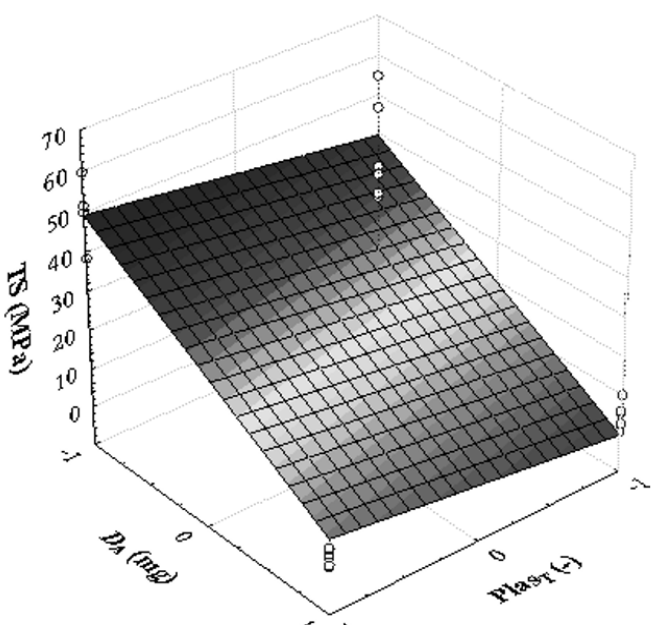

(A)

Figure 4. Response surface plot of tensile strength of the anesthetic buccal films as a function of plasticizer type and drug loading.

$D_{A}\left(X_{4}\right)$ was the factor with the most significant effects by itself, which was also seen in PCA, given that this factor allowed data to be segregated into the two major groups seen in Figure 1 (even and odd numbered). Moreover, $\mathrm{D}_{\mathrm{A}}$ also had significant effects in combination with other factors such as in TS.

$\mathrm{Pol}_{T}\left(\mathrm{X}_{1}\right)$ had a positive effect on $\mathrm{E}$ and $\mathrm{FB}$. Thus, the greater the nominal viscosity of the HPMC and its degree of hydroxypropyl substitution, the greater the E and FB of the films. Plas $\left(\mathrm{X}_{2}\right)$ positively affected TS and FB and therefore the use of mannitol made the films more 
resistant. This finding is also suggested in the PCA model hence TS and FB eigenvector convergence (Figure 1).

The combination of higher viscosity HPMC (i.e., K100 LV) with higher plasticizer loading increased the FB of the films (Table 3). None of the investigated factors significantly affected $\mathrm{Ym}$, which was also suggested by the PCA model, due to Ym eigenvalue relevance in explaining the variance of $\mathrm{PC} 2$, and the minimal convergence it displayed towards the vectors which were better explained by PC1 (all other factors).

The synergic plasticizing effect exerted by the drugs on the films is evidenced, since the increase in $\mathrm{D}_{\mathrm{A}}$ correlated with a linear rate increase on $\mathrm{E}$ (Figures $2 \mathrm{C}, 2 \mathrm{E}$ and $2 \mathrm{~F}$ ). In contrast, this effect made the films more fragile as there was a decrease in FB (Figures 3C, 3E and 3F) and TS (Figure 4A), this trend being also suggested by the negative correlations of these factors' eigenvectors in PCA (Figure 1). Despite the positive effect achieved by the use of mannitol on film resistance when individually analyzed (Figures 3A, 3D, 3E, and 4A), the prediction model presented in Table 3 determines that the association between mannitol and high drug loading level reduces the TS of the films regardless the polymer used.

\subsection{How the film properties correlate with each other?}

The correlation matrix between the properties of mucoadhesive buccal films is presented in Table 4, in which the highlighted values in bold represent the most significant interactions.

Table 4: Correlation matrix between the mechanical properties of the anesthetic buccal films

\begin{tabular}{cccccc}
\hline Variables & T & E & TS & FB & Ym \\
\hline T & 1 & & & & \\
E & +0.79 & 1 & & & \\
TS & -0.90 & -0.69 & 1 & 1 & \\
FB & -0.66 & -0.35 & +0.81 & +0.26 & 1 \\
Ym & -0.37 & -0.29 & +0.28 & +0.26 \\
\hline
\end{tabular}

$\mathrm{T}$, thickness $(\mu \mathrm{m})$; E, elongation (\%); TS, tensile strength (MPa); FB, force at break (N); Ym, Young `s modulus (MPa); $\mathrm{R}^{2}$, determination coefficient of the prediction mathematical model; Coefficients with + and - signs indicate direct and inversely proportional effects, respectively.

None of the dependent variables significantly correlated with Ym. T showed a strong correlation with $E$, demonstrating that thicker films were more elastic. The strong positive correlation between these factors was nonetheless suggested by their eigenvector convergence as seen in the PCA model depicted in Figure 1. It can be noticed that the convergence tends toward the even numbers, so that $D_{A}$ dictates the thickness and the plasticity of the samples. In turn, factors $T$ and E showed a strong negative correlation with TS and low correlation with $F B$, which means that films with greater $D_{A}$ and, consequently $T$, became more plastic, however less resistant when the anesthetics were added to the formulations.

There was a strong positive correlation between TS and FB, but these factors correlated negatively, respectively, in a moderate or weak degree with $E$, this trend being also showcased by their eigenvector convergence in PCA (Figure 1).

\section{DISCUSSION}

The mechanical properties of films play a crucial role in their physical integrity and are also related with their administration and clinical effectiveness. The drug loaded films presented thicknesses ranging from 339.2(68.8) to $427.3(23.1) \mu \mathrm{m}$, which is within the range acceptable for polymeric films intended for drug delivery in the oral cavity i.e., 50 and $1000 \mu \mathrm{m}^{15}$. 
To be applied to the oral cavity, thin films must have adequate elasticity, flexibility, and resistance since they are often removed from the primary packaging, molded and adhered under somewhat stress to the placement site ${ }^{8}$. $E$ is related to the material ' $s$ capability to be permanently (plastically) deformed under stress (tension or traction). TS has been defined as the breaking strength of the material, i.e., the point when a material undergoes from elastic to plastic deformation. FB is the force required to attain the breaking point of a material. In turn, $\mathrm{Ym}$ is related to the evaluation of the stiffness or how the material deforms in the elastic region ${ }^{15}$.

HPMC films are assumed to yield good mechanical properties and coherent structure, which strongly depends on their molecular weight, linear structure (substitution degree), relative humidity, temperature, thickness, production method, type, and ratio of materials incorporated into the films ${ }^{16}$.

According to the literature ${ }^{17}$, films designed for application in the buccal cavity (mucoadhesive or orodispersible) should have the mechanical properties of soft and strong materials i.e., moderate TS, low modulus of elasticity and high degree of elongation. Therefore, all the drug loaded films herein developed met these requirements and thus fitted to the intended purpose, being suitable for buccal administration. For comparison, oral anesthetic films containing $10 \mathrm{mg} / \mathrm{cm}^{2}$ of LDC, prepared using PVP $(10 \% \mathrm{w} / \mathrm{w})$ as the release matrix-forming polymer, high molecular weight chitosan as the mucoadhesive polymer $(2 \% \mathrm{w} / \mathrm{w})$, and propylene glycol $(4.8 \% \mathrm{w} / \mathrm{w})$ as a plasticizer were considered soft and resistant by presenting TS of $0.91 \mathrm{~N} / \mathrm{mm}^{2}, \mathrm{Ym}$ of $0.54 \mathrm{~N} / \mathrm{mm}^{2}$ and $170 \% \mathrm{E}$. ${ }^{18}$.

The remarkable plasticizing effects exerted by the anesthetics in the films have also been reported by our research group when evaluating the effects of metronidazole content on the mechanical properties of resorbable films obtained from tyrosine-based polymer and PEG for the treatment of microbial infections e.g., periodontitis ${ }^{19}$.

Moreover, the effects caused by the synergy between the drugs and mannitol in the TS of the films may be due to the increase in the secondary (weak) interactions with the polymers, since mannitol has double of free hydroxyls for interacting when compared to glycerol, thus yielding a reduction in the glass transition of the polymers. This can also affect the drug release, hydration, and erosion profiles of the delivery systems ${ }^{20}$.

Even though the anesthetic salts were efficient as secondary plasticizers in the films, it was evidenced in complementary tests by our team that some loading of a primary hydrophilic plasticizer is required for the hydration of the samples. In such experiments, mannitol has favored the hydration of the films in a greater extent as compared to glycerol (data not shown). The summation of the results of mechanical properties with those of hydration profiles indicate that mannitol may be the plasticizer of choice in our upcoming investigations, and the evaluation of its effects on the release and promotion of in vitro drug permeation and clinical efficacy of films will be the aim of further investigations.

Mannitol is a pleasant, refreshing, and biocompatible sugar with high water solubility constant and is widely used in pharmaceutical formulations as a sweetener, diluent, and isotonizer ${ }^{21}$. Furthermore, mannitol has enhanced the buccal anesthetic effect of LDC solutions in inferior alveolar nerve block by heightening the drug permeability ${ }^{22}$. These features make it possible to consider mannitol a very versatile component to aid the delivery of local anesthetics in the buccal cavity. Notwithstanding, mannitol effects as plasticizer in anesthetic films have not been investigated so far, which highlights the innovative degree of our work.

Therefore, the following conclusions can be drawn from our findings:

$\checkmark$ QbD approaches such as design of experiments and complementary multivariate statistical tools are useful and prompt strategies for understanding the effects of formulation variables in the mechanical features of buccal drug delivery systems;

$\checkmark$ Regardless of the composition, the anesthetic films presented mechanical properties compatible with the intended purpose in dentistry; 
$\checkmark$ The anesthetic loading was the factor with the most remarkable role in the mechanical properties of the films, exerting a synergic plasticizing effect;

$\checkmark$ Even in very low amounts in the formulations, mannitol as plasticizer made the films more resistant, while glycerol made them more plastic;

$\checkmark$ Decreasing the methoxyl substitution degree and increasing either the hydroxypropyl substitution degree and nominal viscosity of the polymers enhanced the resistance of the films;

$\checkmark$ The use of 3\% w/w HPMC K100LV, 0.24\% w/w mannitol, and PRC and LDC hydrochlorides combined at 1:1 $\left(47 \mathrm{mg} / \mathrm{cm}^{2}\right)$ provides favorable prospects for obtaining the anesthetic buccal delivery platform with adequate mechanical properties.

\section{ACKNOWLEDGMENTS}

The authors gratefully acknowledge Colorcon ${ }^{\circledR}$ do Brasil for supplying the polymers used in this research.

\section{REFERENCES}

1. Couto RO, Cubayachi C, Lopez RFV, de Gaitani CM, Pedrazzi V, de Freitas O. A simple and highresolution HPLC-PDA method for simultaneous quantification of local anesthetics in in vitro buccal permeation enhancement studies. Biomed Chromatogr. 2016;30(6):857-66. http://dx.doi.org/10.1002/bmc.3619. PMid:26379211.

2. Cubayachi C, Couto RO, de Gaitani CM, Pedrazzi V, Freitas O, Lopez RF. Needle-free buccal anesthesia using iontophoresis and amino amide salts combined in a mucoadhesive formulation. Colloids Surf B Biointerfaces. 2015;136:1193-201. http://dx.doi.org/10.1016/j.colsurfb.2015.11.005. PMid:26590633.

3. do Couto RO, Cubayachi C, Calefi PL, Lopez RFV, Pedrazzi V, De Gaitani CM, de Freitas O. Combining amino amide salts in mucoadhesive films enhances needle-free buccal anesthesia in adults. J Control Release. 2017;266:205-15. http://dx.doi.org/10.1016/j.jconrel.2017.09.039. PMid:28974451.

4. Favacho HAS, Couto RO, Duarte MPF, Peixoto MPG, Lopez RFV, Pedrazzi V, Gaitani CM, Freitas O. Synergy between surfactants and mucoadhesive polymers enhances the transbuccal permeation of local anesthetics from freeze-dried tablets. Mater Sci Eng C. 2020;108. http://dx.doi.org/10.1016/j.msec.2019.110373.

5. Jung RM, Rybak M, Milner P, Lewkowicz N. Local anesthetics and advances in their administration An overview. J Pre-Clinical Clin Res. 2017;11(1):94-101. http://dx.doi.org/10.26444/jpccr/75153.

6. Ali F, Bai P, Dungrani H, Raju M, Ustad F, Hassan I. Nature and prevalence of needle phobia among dental college patients. J Dent Res Rev. 2015;2(3):130-3. http://dx.doi.org/10.4103/23482915.169826.

7. Appukuttan DP. Strategies to manage patients with dental anxiety and dental phobia: literature review. Clin Cosmet Investig Dent. 2016;8:35-50. http://dx.doi.org/10.2147/CCIDE.S63626. PMid:27022303.

8. Morales JO, Mcconville JT. Manufacture and characterization of mucoadhesive buccal films. Eur J Pharm Biopharm. 2011;77(2):187-99. http://dx.doi.org/10.1016/j.ejpb.2010.11.023. PMid:21130875.

9. Pramod K, Tahir MA, Charoo NA, Ansari SH, Ali J. Pharmaceutical product development: A quality by design approach. Int J Pharm Investig. 2016;6(3):129-38. http://dx.doi.org/10.4103/2230973X.187350. PMid:27606256.

10. Oh CM, Heng PWS, Chan LW. A study on the impact of Hydroxypropyl Methylcellulose on the viscosity of PEG Melt suspensions using surface plots and principal component analysis. AAPS PharmSciTech. 2015;16(2):466-77. http://dx.doi.org/10.1208/s12249-014-0204-x. PMid:25370022.

11. Sutariya V, Groshev A, Sadana P, Bhatia D, Pathak Y. Artificial neural network in drug delivery and pharmaceutical research. Open Bioinform J. 2014;7(1):49-62. http://dx.doi.org/10.2174/1875036201307010049.

12. Zane $P$, Gieschen H, Kersten E, Mathias N, Ollier C, Johansson P, Van den Bergh A, Van Hemelryck S, Reichel A, Rotgeri A, et al. In vivo models and decision trees for formulation development in early 
drug development: A review of current practices and recommendations for biopharmaceutical development. Eur J Pharm Biopharm. 2019;142:222-31. http://dx.doi.org/10.1016/j.ejpb.2019.06.010. PMid:31233862.

13. Ferreira AP, Tobyn M. Multivariate analysis in the pharmaceutical industry: Enabling process understanding and improvement in the PAT and QbD era Multivariate analysis in the pharmaceutical industry. Pharm Dev Technol. 2015;20(5):513-27. http://dx.doi.org/10.3109/10837450.2014.898656. PMid:24641280.

14. ASTM [Internet]. Standard test method for tensile properties of thin plastic sheeting. vol. 14. West Conshohocken, Pensilvânia: ASTM; 2002.

15. Nair AB, Kumria R, Harsha S, Attimarad M, Al-Dhubiab BE, Alhaider IA. In vitro techniques to evaluate buccal films. J Control Release. 2013;166(1):10-21. http://dx.doi.org/10.1016/j.jconrel.2012.11.019. PMid:23219961.

16. Ghadermazi G, Hamdipour S, Sadeghi K, Ghadermazi R, Khosrowshahi Asl A. Effect of various additives on the properties of the films and coatings derived from hydroxypropyl methylcellulose: A review. Food Sci Nutr. 2019;7(11):1-15. http://dx.doi.org/10.1002/fsn3.1206.

17. Mashru RC, Sutariya VB, Sankalia MG, Parikh PP. Development and evaluation of fast-dissolving film of Salbutamol Sulphate. Drug Dev Ind Pharm. 2005;31(1):25-34. http://dx.doi.org/10.1081/DDC43947. PMid:15704855.

18. Mahrous GM, Shazly G, Zidan DE, Zaher AAA, El-Mahdy M. Formulation and evaluation of buccoadhesive films of lidocaine hydrochloride. J Adv Biomed Pharm Sci 3 2020;3:53-9.

19. Couto RO, Sommerfeld SD, Dube K, Freitas O, Kohn J. Preliminarily development of a moistureactivated bioresorbable polymeric platform for drug delivery. Quim Nova. 2015;38:902-9. http://dx.doi.org/10.5935/0100-4042.20150118.

20. Jennings $C L$, Dziubla TD, Puleo DA. Combined effects of drugs and plasticizers on the properties of drug delivery films. J Bioact Compat Polym. 2016;31(4):323-33. http://dx.doi.org/10.1177/0883911515627178. PMid:27821905.

21. Rowe RC, Sheskey PJ, Quinn ME. Handbook of pharmaceutical excipients. 6th ed. London: Pharmaceutical Press; 2009. https://doi.org/10.1016/S0168-3659(01)00243-7.

22. Kumar A, Khanna R, Srivastava RK, Ali I, Wadhwani P. Mannitol an adjuvant in local anaesthetic solution: recent concept \& changing trends. J Clin Diagn Res. 2014;8(11):GE01-04. http://dx.doi.org/10.7860/JCDR/2014/9629.5187. PMid:25584240.

\section{Authors' contributions}

ROC, OF, VP and RFVL: Funding acquisition; Conceptualization; Experimental design; Project administration; formal analysis; writing; LFMF and MPFD: Performing experiments, data acquisition and interpretation; data curation; writing; DVT: formal analysis; writing; language review. 